\title{
As transformações do direito de família
}

\section{Lino de Morais Leme}

(Catedrático de Direito civil)

\section{I - A família primitiva}

§ 1. A primeira forma social foi a familia. O instinto do sexo ligado ao egoismo determina as ligações; o instinto da paternidade, sobrevindo, e a necessidade de apoio mútuo, determinam a estabilidade da união. E assim se formou a célula social.

Se é verdade, como diz Lubbock (1), que nas raças inferiores é quasi desconhecido o amor, incontestável é que os instintos, o poder e a necessidade de união na luta pela vida levariam ao respeito desses agrupamentos. A natureza e as feras não podiam ser dominadas sem a união dos grupos, e uns não poderiam se impôr aos outros, sem a solidariedade, que a conjugação de esforços já revela.

$\mathrm{E}$ assim se estabelece o costume, que vem a ser reconhecido nas organizações sociais, desde as mais primitivas.

A poligamia resultou da preponderância do varão e do maior número de mulheres. Pode admitir-se tenha havido a poliandria, pelo fenômeno inverso, mas fórma evidentemente passageira. Não se pode interpretar diferentemente os fatos referidos pelos escritores.

A compra da mulher deve ter representado uma compensação pela perda do auxílio que a mesma prestava, com seus serviços, à família paterna, da mesma fórma que

(1) Les origines de la civilisation. 
o dote veio a representar o auxílio que a concentração de capitais permitia ao pai (ou à própria mulher, ou a outra piessôa) fornecer ao marido, para tornar menos pesados os encargos advindos do casamento.

2. A monogamia e a poligamia se instalam na organização social. Entre os hebreus, se admitia a poligamia e se permitia fossem tomadas, como concubinas, as escravas e as servas das mulheres. O direito muçulmano limita a quatro as mulheres legítimas com certos direitos e deveres, além das concubinas, se o marido não se comprometeu a ficar monógamo, bígamo ou trígamo. Na Índia se admite o casamento, exceto para os sudras, embora se aconselhe a monogamia, como a fórma perfeita; o homem de casta superior, casando-se com mulher de sua casta, pode descer a série de castas; o varão de casta inferior não póde, porém, pôr os olhos em mulher de casta superior. Na China, o casamento é monogâmico, mas o homem pode ter até tres concubinas.

Com o advento do Cristianismo, não se admite senão o casamento monogâmico.

3. A forma patriarcal da familia é a que predomina. Entre os romanos, a família era uma unidade legal, econômica e religiosa, caraterizando-se pelos poderes extensos que tinha o pater famílias. Já entre os germânicos, o marido e a mulher tinham direitos iguais, e o filho, atingindo a maioridade, se tornava independente.

Em alguns povos, em estado atrazado de civilização, não ha vocábulos distintos para indicar o sobrinho e o neto, que são abrangidos na designação "filho"; bem assim o tio, que é indicado por "pai segundo, menor" (Birmânia, Japão), "pai varão" (Hawaï). 


\section{II - Casamento}

4. Na China há o casamento por compra. O Direito muçulmano admite a poligamia, mas reconhece a cada mulher o direito de ter habitação separada. Na China, ha uma monogamia original, pois, se a mulher é uma só, contudo o marido póde ter até tres concubinas.

Mas, vamos referir-nos apenas aos países que admitem a verdadeira monogamia: um só marido e uma só mulher.

5. Em geral, o casamento é regulado pela religião. Em alguns países, não se reconhece o casamento religioso; em outros se permite aos nubentes escolher entre o casamento religioso ou o civil. Assim na Inglaterra, Espanha (art. 76 do Código Civil), Suécia (1809), Finlândia (1917), Noruéga (1918), Checo-eslováquia (1919), Letônia (1921), Dinamarca (1922), Itália (1929), Perú (1936), Brasil (1937). $\mathrm{Na}$ Grécia, sòmente se admite o casamento religioso. $\mathrm{Na}$ França, Rússia, Alemanha Austria, Suiça, Venezuela, Iuguslávia (1946), Polônia (1948), Rumânia, só se reconhece o casamento civil.

Na Suécia, a coabitação, precedida de esponsais, é casamento imperfeito. O mesmo se dá na Noruéga, quando resulta gravidês. Na Dinamarca, a coabitação, em certas condições, obriga a casamento. Na Escóssia, ha o casamento "by habit and repute".

6. Quanto ao conceito de casamento (ato, contrato, instituição), é matéria doutrinária. O Direito canônico o considera contrato-sacramento; e, como contrato, reconhece a igualdade jurídica do marido e da mulher, proclamada por Leão XIII, na encíclica Arcanum.

O casamento é uma instituição social. Só a religião pode considerá-lo sacramento ou instituição divina. 
7. Os esponsais ainda são reconhecidos em alguns países - Alemanha, Suiça, Inglaterra, Estados Unidos (menos em oito Estados, entre os quais, Nova Iorque, Nova Jersey, Pensilvânia, Illinois), Perú (também para os de menor idade - art. 76 do Código Civil), países escandinavos (na Suécia, cria um impedimento matrimonial).

8. A idade para casar varia: a) em vários paises, é a de 18 e 16 anos, respetivamente, para o homem e a mulher: Portugal, Brasil, Estados Unidos, China, Rússia, Iuguslávia, Rumânia; b) 14 e 12 anos, em outros: Espanha, Grécia e em vários países da América do Sul - Colômbia, Venezuela, Bolívia, Uruguai, Chile, Argentina; c) 18 e 15, na França; d) 20 e 19, na Suiça; e) 16 e 14, no México; f) 18 e 17, na Turquia; g) 21 (maioridade) e 16, na Alemanha. Na Inglaterra a idade é a mesma, para o homem e a mulher: 16 anos.

9. Para aumentar o número de casamentos, afim de colocar as uniões do homem e da mulher de acôrdo com a lei, alguns paises tomam providências especiais, como fêz o Chile, pela lei ${ }^{\circ} 4808$, de 1930 , a qual, considerando que muitas pessoas vivem em concubinato, por ignorância, obriga os oficiais do Registro Civil a visitas periódicas, para aconselhar o casamento, sôbre tudo aos que têm filhos. Com o mesmo objetivo se estabelecem nútuos para casamento (como a nossa lei n. 3.200), auxílio aos pais para educação dos filhos (França - Código da familia).

$\mathrm{Na}$ Rússia, depois de implantado o comunismo, admitiu-sc o casamento "de fato", semelhante ao concubinato, que existiu em Roma, e ao casamento imperfeito, na Suécia; mas o dispositivo do Código russo đe 1918 foi abrogado em 1944, estabelecendo-se não haver casamento sem o respetivo registro. Mas, na maioria dos paises, casamento é um ato solene, para resguardar a liberdade dos nubentes. 
10. Quanto aos impedimentos matrimoniais, na linha reta, não há discrepância, a não ser quanto ao resultante da aliança, para o qual o Código alemão admite dispensa, e o Código francês também, mas este só no caso de morte (art. 164). As divergências se manifestam quanto aos impedimentos na linha colateral, e aos de ordem moral e eugênica.

Limitam o impedimento, na linha colateral, ao segundo grau, as leis da Dinamarca, Noruéga, Alemanha (Código Civil, art. 1310), Holanda (Código Civil, art. 87), Uruguai (Código, art. 91), Argentina (Lei do casamento civil, art. 92), Chile (Lei do casamento, art. 4). E extendem. ao $3^{\circ}$ grau os Códigos Civis da Suiça (art. 100), da França (art. 163) do Perú (art. 83) da Itália (art. 87), do México (art. 156), do Brasil (art. 183, n. IV, salvo a hipótese prevista na lei n. 3200), Venezuéla (arts. 52 e 53, vedando até o casamento entre tios e sobrinhos), o Direito muçulmano, send̃o que alguns admitem dispensa, quanto ao parentesco colateral em $3^{\circ}$ grau (Código francês (art. 164), mexicano (art. 156). Na história do E'gito se encontram casos de casamentos entre irmãos. $\mathrm{Na}$ Pérsia, seguido referência no Zend-Avesta e em outros documentos, é permitido o casamento entre irmãos, e até o incesto, na linha reta; mas será assim hoje? No direito hebraico o casamento entre parentes só é admissível no caso de levirato.

11. Quanto ao impiedimento por adoção, não existe, como é natural, nos países que não a reconhecem (Portugal, Holanda); e, dos que a regulam, uns limitam o impedimento ao adotante e ao adotado, e a seus cônjuges (França, Luxemburgo, Suiça, Espanha), e outros incluem no impedimento os descendentes dos mesmos (Código alemão, art. 1311; Código mexicano, art. 156; Código peruano, art. 83; Código italiano, art. 87; Código venezuelano, art. 55). O Código de direito canônico também se refere à adoção (art. 1067 a 1800). O Código venezuelano proibe o casamento 
entre o cônjuge do adotado e o adotante e entre o adotado e o cônjuge do adotante, enquanto durar a adoção.

12. Dentre os impedimentos morais há o decorrente da cumplicidade no adultério, que foi suprimido na França, Suiça, Itália, Portugal, países escandinavos, etc., sendo poucas as legislações que aĩnda o conservam (Código alemão, arț. 1912; holandês, art. 89; português, art. 1058; mexicano, art. 156; lei chilena sôbre o casamento, art. 4). Mas o resultante de homicídio contra o outro cônjuge é consagrado no Código português (art. 1058), Uruguai (art. 81), venezuelano (art. 55), italiano (art. 88), lei argentina (art. 14), lei chilena (art. 4), etc. No direito mulçumano há impedimento entre os criados pela mesma ama.

13. Outros impedimentos são estabelecidos em algumas legislações :

a) para resguardar a liberdade dos nubentes - o do raptor com a raptada, o do tutor e curador com o tutelado e o curatelado (Cód. espanhol art. 115; cubano, art. 115), português (art. 1058); peruano (art. 83); brasileiro (art. 183, ns. X e XI);

b) de caráter eugênico: a) alienação mental (lei argentina, art. 12; lei russa de 1944; Código mexicano, art. 156; Código peruano, art. 82; mexicano, art. 156); c) sífilis, lepra e enfermidades venéreas (Dinamarca, Noruéga, Bélgica, Estônia, México); d) embriaguês habitual, e uso de drogas heróicas (México);

c) a diferença de castas, na Índia.

Na Itália, conforme o art. 91 do Código Civil, os casamentos das pessôas pertencentes a raças diversas está sujeito às limitações estabelecidas por leis especiais.

14. O divórcio é admitido na Europa, exceto na Itália e na Espanha; e na América, exceto no Brasil, Argentina e Chile. 


\section{III — Pátrio Poder}

15. A maioridade é fixada em 21 anos, na França, Inglaterra, Alemanha, Portugal, Uruguai, Colômbia, Austria, Suécia, México (mas aí, até aos 25 anos, é necessária licença para se casar); em 20 na Suiça, no Japão; em 18, na Rússia; em 22, na Argentina; em 23, na Espanha; em 25, na Noruega, na Dinamarca, no Chile, no direito muçulmano (neste, o menor púbere póde dispôr de sua pessôa, mas só aos 25 anos pode fazê-lo quanto aos bens). A puberdade é aos 15 anos, no rito henefita; aos 18, no malekita; aos 15 e 9 , respetivamente para o homem e mulher, no rito chiita.

16. Em matéria de filiação, de se notar que a concepção antiga sôbre filiação(legitimidade, reconhecimento) e pátrio poder se tem modificado sob influxo de ordem moral e econômica. A orientação do Direito Romano, que dava ao paterfamilias poderes absolutos (2), sofreu o influxo da do Direito germânico, no qual a família é organizada sob o critério da igualdade. As doutrinas individualistas do século XVIII, que foram a base do Código civil francês, deviam naturalmente concorrer para o fortalecimento do critério germânico; e as necessidades econômicas deviam ir desenvolvendo o reconhecimento dos direitos dos filhos e o amparo aos menores. Assim, póde reconhecer-se, com Charmont, que o pátrio poder obedece a duas concepções: os direitos e deveres dos pais para com

(2) As leis das XII Tábuas falavam no direito de o pai prendê-los, açoitá-los, tê-los sob cadeias, em trabalhos rústicos, vendê-los, ainda que desempenhassem cargos elevados na República.

No direito hebraico, também o pai era, ao mesmo tempo, magistrado, sacerdote e senhor da vida e dos bens dos filhos (Goldstein, Derecho hebreo).

Já entre os chineses, o pai tem um poder bem grande sôbre o filho, porém não absoluto (Frei João Batista, Se Tsien Kaó, La filosofia social $y$ politica del confucionismo. 
os filhos, como faz o Código Civil do Perú, art. 390. A Association Henri Capitant pour le développement de la culture juridique française tem propugnado por leis que extendam o contrôle judiciário a todos os casos em que a saúde, a moralidade ou a educação da criança são comprometidas ou insuficientemente salvaguardadas pelos pais; nêsse sentido a lei francesa de 24 -VIII-1889, revista pela de 15-XI-1921 e pelo decreto-lei de 30-X-1935.

Com essa orientação, os códigos ou convenções internacionais estabelecem que é a lei do filho a que lhe regula a situação, os casos de perda do pátrio poder, a tutela e curatela, bem assim o reconhecimento da filiação natural, e que se deve ter em conta as leis nacionais do adotante e do adotado, para a adoção. Assim estabeleceram a Convenção de Haia de 12-VI-1902, a de 17-VII-1905, o Código Bustamante, arts. 57-97.

\section{IV - Filiação legítima}

17. Entre os filhos legitimos se incluem os legitimados, em virtude de casamento putativo, havendo boa fé por parte de um dos cônjuges (na Suiça, mesmo que haja má fé de ambos), e em alguns países (Dinamarca, Suécia, Noruega, Suiça), quando houve esponsais, não se havendo celebrado o casamento, por morte ou incapacidade de um dos pais. Na Venezuéla, só podem ser legitimados os filhos naturais (art. 227).

A legitimação pelo casamento não exige reconhecimento prévio.

Em alguns países, ha a legitimação por rescrito do. poder público, de origem romana (conservado na Itália, Portugal, Holanda, Suiça, Polônia, Grécia e países da America Latina), quando impossivel o casamento por morte de um dos pais ou por vida dissoluta da mãe. O Código venezuelano admite a legitimação dos filhos mortos, quando deixaram descendentes (art. 228). 
18. O prazo máximo da gestação para o filho ser considerado legítimo é, geralmente, de 300 dias (Código brasileiro, art. 338; francês, 314; italiano, 232; espanhol, 108; português, 101; argentino, 240; suiço, 254; chileno, 76; uruguaio, 191; peruano, 301; mexicano, 324; venezuelano. 197).

Alguns Códigos dilatam êsse prazo para: 302 dias (Código alemão, art. 1.592) ; 306 dias, Código russo; 307 dias, Código austriaco; 320 dias, Código belga; 323 dias, Código holandês. Com efeito, LitTré e RoHin (3) dizem que não é muito raro ver-se a gestação atingir 308 dias e mesmo 316 dias; e alguns autores elevam mesmo êsse limite: Winkel, para 334 dias; Bensiger, para 336; Fuchs, para 341.

\section{V - Filiação natural}

19. Em regra as legislações consagram o direito de o filho investigar a paternidade, dìvergindo, porém, quanto aos adulterinos e incestuosos, cujo reconhecimento é proibido (Cód. francês, art. 335; suiço, art. 304; argentino, art. $314)$.

A lei portuguêsa de proteção aos filhos, de 25-XII-1910, art. 22, se limita a proibir o reconhecimento dos incestuosos. Entre nós, depois do decreto n. 883, de 1949, se admite a legitimação dos filhos havidos fóra do casamento, depois de dissolvida a sociedade conjugal. A questão sôbre ser adulterino ou não o filho do desquitado, já havia sido superada pelo decreto-lei $\mathrm{n}^{\circ} 4.437$, de 1942.

20. A jurisprudência francesa (Savatier (4), admite, nos casos de fins de non recevoir, uma ação que êle chama "pecuniária", e que corresponde à ação de alimentos. Em nosso direito se reconhece aos filhos, que não podem ser reconhecidos, o direito a alimentos.
(3) Dictionnaire de médecine.
(4) Recherche de la paternité. 
N'ota-se, porém, uma tendência para se admitir o reconhecimento dos filhos adulterinos, com uma disposição de caráter geral, proibindo-se a revelação do nome da pessôa com quem foi havido (Código mexcano, art. 370), ou, como no Código italiano, art. 252, pelo genitor que, ao tempo da concepção, não estava casado. Quanto aos filhos incestuosos, perdura a proibição do reconhecimento, para o qual o Código italiano (art. 251) estabelece uma exceção, permitindo-o ao genitor que ignorava o vínculo existente.

21. Relativamente ao direito de sucessão dos filhos naturais :

a) não o reconhece a Inglaterra;

b) só o admitem, na sucessão da mãe e dos ascendentes dela - Áustria, Rumânia, Venezuela;

c) equiparam-nos aos legítimos, na sucessão materna - Noruega (se tiver havido reconhecimento voluntário), Luisiana, Suiça (Código, art. 461). Aí se lhes concede, no caso de reconhecimento ou de declaração de paternidade, na família paterna, metade do que receber o filho legítimo;

d) só lhes reconhede direito, na sucessão paterna, quando tiver havido manifestação expressa da vontade do pai - a Suécia;

e) só thes reconhece o direito a alimentos - Chile (art. 28);

f) dão-Ihes metade do que receber o filho legitimo - Código francês, art. 758; suiço, 461; italiano, 574; venezuelano, 823; brasileiro, 1605 , parag. $1^{\circ}$; espanhol, 840 (êste dentro da terça disponível, e $1 / 4$, se concorrer com ascendentes) ;

g) dão-lhes cotas diferentes; I) o Código uruguáio, art. $887,2 / 3$ do que receber o filho legítimo, quando com êle concorra; $1 / 2$ da porção legitimária, quando concorra com ascendentes legítimos, e 1/2 da herança, se não os houver; II) o Código português, art. 1785: 2/3 do que receber o legítimo, se perfilhado antes do casamento; $1 / 2$, dentro da 
cota disponível, se perfilhado depois; III) o Código belga, art. 757: 1/3, se concorrem com filhos legitimos; 1/2, se o concurso fôr com ascendentes ou irmãos; $3 / 4$ se não houver êsses herdeiros.

22. Em França, êles não podem receber doações inter vivos que ultrapassem suas cotas hereditárias, nem legado, pela porção disponível, que os coloque em situação superior à do filho legítimo (art. 908); e não têm direito sucessório aos bens dos avós (art. 757). O Código italiano, que concede ao filho natural metade do que couber ao filho legítimo, subordina êsse direito à circunstância de a cota dos legitimos não ser inferior a um têrço da herança, e permite, aos descendentes legítimos, pagar, em dinheiro ou em imóveis da herança, a parte que competir aos filhos naturais (art. 574).

\section{VI - Filiação adotiva}

23. Como vimos, a propósito dos impedimentos matrimoniais, vários códigos não se referem à adoção, que o Direito Romano regulou, pela necessidade de conservar e manter o culto doméstico, provendo à falta de filhos que perpetuassem o culto aos deuses lares. Havia, nesse Direito, tres espécies de adoção: I) a de alieni juris - datio in adoptionem - adoção em sentido restrito; II) a dos sui juris, dos não sujeitos ao pátrio poder - arrogatio, com os seguintes efeitos: a) submeter, ao pátrio poder do arrogante, o arrogado e os filhos que the estavam submetidos; b) dar, ao arrogado, todos os direitos de filho-família; III) a adoção por testamento, que exigia a confirmação curial.

24. Quanto à idade para adotar, variam as legislações, exiginco: a) 50 anos, o nosso Código e os da Bolívia, Perú, Alemanha, Itália; b) 45 anos, o Código espanhol (art. 173), 
o cubano; 40, o Código da Venezuéla (art. 248), o do México (art. 390), o da Suiça, (art. 264), o da França (art. 344), o da Itália (art. 291), o da Guatemala (por este, sendo casado, não ha limite), o da Costa Rica (para os casados ha mais de 10 anos, o limite é restringidó a 30 anos); 35, o da Bélgica; 30, o do Uruguai, o do Equador; 25 anos, o Direito escandinavo e o inglês; 21, o Código da Colômbia.

A diferença de idade entre o adotante e o adotado, que era de 18 anos no Direito Romano, é assim regulada no Direito moderno: a) conserva o critério romano a maioria dos códigos: alemão (art. 1744), suiço (264), italiano (291), peruano (326), uruguaio (art. 243), lei argentina; b) reduzem o limite para 17 anos, o Cód. mexicano (art. 390) e o italiano; o) reduzem-no para 15, o Cód. francês (art. 343), o espanhol (art. 173), o belga, e o os de vários países sul americanos (Chile, Bolivia, Colômbia, Costa Rica, República Dominicana); d) elevam-no para 20, o Equador, o Canadá; e) eleva-o para 24, o direito inglês.

25. O Cód. da Colômbia (art. 273) sòmente permite a adoção entre pessoas do mesmo sexo, salvo se os adotantes forem marido e mulher. Também na Inglaterra a adoção de pessoas de sexo oposto ao do adotante, só em casos especiais.

26. A controvércia sôbre se os filhos do adotado sucedem ao adotante é resolvida no sentido afirmativo por alguns Códigos (taliano, art. 468; suiço, art. 465; francês, 357; peruano, art. 333 (5). Entre nós, a doutrina é vária: a) são pelo direito de os filhos do adotado representarem o pai, na sucessão do adotante - Clovis ( ), Itabaiana de Oli-

(5) Esse c'ódigo dispõe que a adoção confere ao adotado a qualidade do filho legítimo do adotante (art. 332), e que o parentesco se limita ao adotante, o adotado e descendentes legítimos deste (art. 333).

(6) Ciódigo Civil, comentário ao art. 1618. 
veira (7), Pontes de Miranda (8), Tito Fulgêncio (9); b) contrária é a opinião de Hermenegildo de Barros (10), de Carlos Maximiliano (12), este invocando opiniões de Baudry Lacantinerie et Wairl, Aubry et Rau, Huc, DemoLOMBE.

Em geral, porém, os Códigos apenas dispõem que o parentesco resultante da adoção é meramente civil e se limita ao adotante e ao adotado, como o nosso Código; de que o filho adotivo não tem direito sucessório na família do pai do adotante, e recìprocamente, como o Cód. da Venezuela (art. 828) e do México (art. 1.611).

\section{VII - A instituição da família}

27. A evolução do direito de família está ligada às transformações sociais. Com a desagregação da família, no sentido do direito romano, operada pela separação de membros da mesma, levados pelas necessidades econômicas e pelas tendências individualistas, que dominaram na segunda metade do século XIX, ficou ela restringida à ligação entre pais e filhos. Daí o enfraquecimento do direito sucessório dos parentes colaterais.

As idéias de liberdade levaram a restringir o pátrio poder e a melhorar a situação da mulher casada, suprimindo-se o dever de obediência, a incapacidade, e apenas conservando-se as restrições què decorrem de se reconhecer, ao marido, a chefia da sociedade conjugal.

(7) Direito das sucessões.

(8) Direito de familia, parag. 160.

(9) Programa de Direito Civil, p. 245.

(10) Manual do Cód. Civil, col. Paulo de Lacerda, vol. XVIII n. 350 .

(11) Manual de Direito Civil, vol. 1, § 199.

(12) Direito das sucessões, vol. 1, § 278. 
Diversas causas vêm acarretando uma crise na instituição da família, devido à aproximação dos dois sexos nas oficinas e nas lojas, ao enfraquecimento do sentimento religioso, ao afrouxamento das idéias morais - o que vem mostrar a necessidade de seu cuidar sèriamente desta instituição. Salvá-la é salvar a Pátria. A desorganização dessa unidade social, moral, econômica e jurídica, que é a família, acarretaria a decadência do civismo, pondo em perigo a independência da Pátria, em tôrno de cuja idéia se desenvolvem os sentimentos de solidariedade entre os homens. 